\title{
Metastatic Vaginal Carcinoma
}

National Cancer Institute

\section{Source}

National Cancer Institute. Metastatic Vaginal Carcinoma. NCI Thesaurus. Code C156065.

A carcinoma that arises from the vagina and has metastasized to another anatomic site. 